\title{
Chlamydial infections of the urethra in women
}

\author{
M G BRADLEY,* D HOBSON,† N LEE,† I A TAIT,* AND E REES* \\ From the *Department of Genitourinary Medicine, Royal Liverpool Hospital, Liverpool, and the \\ †Department of Medical Microbiology, University of Liverpool, Liverpool
}

SUMMARY Cervical and endourethral swabs from 360 untreated women attending a sexually transmitted disease (STD) clinic were cultured for Chlamydia trachomatis and other genitourinary pathogens. The patients included contacts of men with non-gonococcal urethritis, women with gonorrhoea, and those in whom symptoms suggestive of urinary tract infection were the main reasons for their attendance. Chlamydial infection of the urethra was less common than, and seldom occurred in the absence of, cervical chlamydial infection; it was frequently silent, producing no signs or symptoms of urethritis. Only 33/96 women with evidence of urethritis gave chlamydia positive urethral swabs, and 14 of them had other concurrent infections of the genitourinary tract. Chlamydia trachomatis thus does not appear to be a major cause of the signs and symptoms of urethritis commonly found in women attending STD clinics, and there seems to be no indication for taking routine urethral swabs to aid in the diagnosis of chlamydial infection in women.

\section{Introduction}

Chlamydia trachomatis is now generally accepted as being the most common cause of acute and clinically overt non-gonococcal urethritis (NGU) in men. In women, however, even in known consorts of men with NGU, urethral swabs are not routinely examined for chlamydial infection despite the fact that symptoms of urinary tract infection are common in women attending sexually transmitted disease (STD) clinics.

The favoured procedure for seeking laboratory confirmation of chlamydial infection in women is to take only cervical swabs. Undoubtedly cervical infection is common. In a single STD clinic in Liverpool we have found cervical infection in $21 \%$ of the general female patients, in $35 \%$ of women contacts of men with NGU, and in $51 \%$ of women with untreated gonorrhoea. ${ }^{12}$ These infections are often silent, as they are in gonorrhoea. It seemed possible that equally silent infections of the urethra might also be common, and that routine examination of urethral swabs might increase the detection rate of chlamydial infection in women.

Address for reprints: Dr D Hobson, Department of Medical Microbiology, The Medical School, University of Liverpool, Liverpool L69 3BX

Accepted for publication 14 January 1985
In the past few years there have been divergent reports on the incidence and clinical importance of chlamydial infections of the urethra in women. These will be discussed below in relation to the findings of the present study, in which we set out to investigate (1) the frequency with which the urethra might be the sole site from which a laboratory diagnosis of chlamydial infection could be made, (2) the incidence of positive urethral swabs in women who also have chlamydia positive cervical swabs, and whether isolation of $C$ trachomatis from the urethra might thus represent contamination from infected cervical secretions rather than a true established infection of urethral mucosa, and (3) the relation between urethral infection and symptoms or objective signs of urethritis in women.

\section{Patients and methods}

We examined 360 women on their first visit to a single STD clinic in the Royal Liverpool Hospital. None had received antibiotics in the previous month. This study population comprised 71 women with gonorrhoea, 122 who were contacts of men with NGU, and 167 with miscellaneous reasons for attendance. Women in the first two groups were unselected consecutive new patients in some of whom symptoms or signs of urethritis were an incidental finding. In the third group signs or symptoms suggesting urethritis were the presenting features and 
the main reason for examination in about $60 \%$ of the women examined, and the rest were unselected consecutive new patients.

All patients were asked specifically about present symptoms of frequency of micturition, nocturia, painful micturition, dyspareunia, vulval or vaginal irritation, use of chemical irritants, and recent changes in sexual partners. Examination included a search for urethral congestion or oedema, urethral mucopus or mucoid secretion, and in most cases microscopical examination of urethral secretions for the presence of polymorphonuclear leucocytes (PMNL).

Cervical, urethral, and vaginal swabs were taken with care to avoid cross contamination between the sites. Endourethral specimens were taken after the perimeatal area had been wiped anteroposterially with a sterile swab. Any urethral exudate was then obtained by introducing a finger into the vagina and gently massaging the length of the urethra. A fine metal nasopharyngeal swab tipped with cotton wool was then inserted $1 / 2 \mathrm{~cm}$ to $1 \mathrm{~cm}$ into the urethral orifice and gently rotated to obtain the specimen. No disinfectant or other cleansing fluid was used.

Laboratory examination for Neisseria gonorrhoeae, other bacterial pathogens, Trichomonas vaginalis, and yeasts was by conventional methods described previously. ${ }^{3}$ Cervical and urethral swabs were cultured for $C$ trachomatis by inoculating cycloheximide treated McCoy cells with centrifuge assisted absorption. Cultures were examined by dark

\section{Results}

INCIDENCE OF CHLAMYDIAL INFECTION

$C$ trachomatis was isolated from the cervix or urethra, or both, of $115(32 \%)$ of the 360 women (table I). The incidence of infection was $43 \%$ $(52 / 122)$ in sexual contacts of men with NGU, $52 \%$ $(37 / 71)$ in women with concurrent gonorrhoea, but only $16 \%(26 / 167)$ in the women with miscellaneous concurrent conditions.

\section{INCIDENCE OF ISOLATION OF CHLAMYDIAE FROM URETHRA}

Positive results were obtained from $110(96 \%)$ cervical swabs, but from only $71(62 \%)$ urethral swabs from the 115 women infected with chlamydiae (table I). The positive urethral swabs came from 33 $(63 \%)$ of the 52 contacts of men with NGU, $18(49 \%)$ of the 37 women with concurrent gonorrhoea, and 20 $(77 \%)$ of the 26 women with miscellaneous concurrent conditions. The difference between cervical and urethral isolation rates overall was significant $\left(\chi^{2}=37 \cdot 4 ; p<0 \cdot 001\right)$, but the differences in urethral isolation rates between the groups of women were not.

RELATION OF POSITIVE RESULTS FROM CERVIX AND URETHRA

Both the cervix and urethra gave positive results in 66 $(57 \%)$ of the 115 infected women (table I), whereas the cervix was the sole site yielding positive results in

TABLE I Incidence of isolation of Chlamydia trachomatis from paired cervical and urethral swabs from 360 women

\begin{tabular}{|c|c|c|c|c|c|c|}
\hline \multirow[b]{2}{*}{$\begin{array}{l}\text { Condition concurrent } \\
\text { with chlamydial infection }\end{array}$} & \multicolumn{3}{|c|}{ No of women yielding chlamydiae from: } & \multirow[t]{2}{*}{$\begin{array}{l}\text { Total (\%) } \\
\text { positive }\end{array}$} & \multicolumn{2}{|c|}{$\begin{array}{l}\text { No (\% of total positive) } \\
\text { with isolates from: }\end{array}$} \\
\hline & $\begin{array}{l}\text { Cervix } \\
\text { only }\end{array}$ & $\begin{array}{l}\text { Cervix }+ \\
\text { urethra }\end{array}$ & $\begin{array}{l}\text { Urethra } \\
\text { only }\end{array}$ & & Cervix & Urethra \\
\hline $\begin{array}{l}\text { Contacts of men with NGU }(n=122) \\
\text { Gonorrhoea }(n=71) \\
\text { Miscellaneous }(n=167)\end{array}$ & $\begin{array}{r}19 \\
19 \\
6\end{array}$ & $\begin{array}{l}32 \\
17 \\
17\end{array}$ & $\begin{array}{l}1 \\
1 \\
3\end{array}$ & $\begin{array}{l}52(43) \\
37(52) \\
26(16)\end{array}$ & $\begin{array}{l}51(98) \\
36(97) \\
23(88)\end{array}$ & $\begin{array}{l}33(63) \\
18(49) \\
20(77)\end{array}$ \\
\hline Total $(n=360)$ & 44 & 66 & 5 & $115(32)$ & $110(96)$ & $71(62)$ \\
\hline
\end{tabular}

$\mathrm{NGU}=$ non-gonococcal urethritis.

ground microscopy after staining with Giemsa, and positive cultures were recorded quantitatively in terms of the number of inclusion forming units (ifu) of $C$ trachomatis/McCoy culture coverslip. All specimens were examined on the day of sampling or within 24 hours after being stored at $4^{\circ} \mathrm{C}$. Details of these laboratory methods have been described previously. ${ }^{13}$

The statistical evaluation of all results was by the $\chi^{2}$ test with Yate's correction for continuity.
$44(38 \%)$ and the urethra was the sole site in only five (4\%). There were no significant differences between the three groups of women in these respects.

Chlamydial inclusion counts on each positive specimen showed that $48(68 \%)$ of the positive urethral swabs came from women with low cervical counts ( $<1000 \mathrm{ifu}$ /coverslip) or with negative cervical cultures (table II). Conversely, 11/34 (32\%) women with high cervical counts (a range of 1000 to 78000 ifu/coverslip) did not have positive urethral cultures. 
TABLE II Positive urethral cultures in relation to positive cervical cultures from 115 women infected with chlamydiae

\begin{tabular}{lllllllll}
\hline \multicolumn{7}{l}{ No with inclusion counts (ifu/coverslip) of: } & & \\
\cline { 2 - 9 } & 0 & $1-10$ & $10-100$ & $100-1000$ & $1000-10000$ & $>10000$ & Total \\
\hline $\begin{array}{lllllll}\text { No of women infected with chlamydiae } \\
\text { No (\%) with positive urethral cultures }\end{array}$ & 5 & 23 & 25 & 28 & 20 & 14 & 115 \\
\hline
\end{tabular}

There was no correlation between the urethral and cervical inclusion counts in women where both swabs were positive. Only 20/71 (28\%) positive urethral swabs yielded more than 100 ifu/coverslip (range 101-3280, mean $=670$ ifu/coverslip), but $12(60 \%)$ of these high urethral counts were in women with low cervical counts.

\section{RELATION OF URETHRAL INFECTION TO URETHRITIS}

The history, clinical, and laboratory findings of the 360 women showed that $96(27 \%)$ had symptoms or signs, or both, suggesting urethritis (table III) (58
To investigate the relationship between chlamydial infection and urethritis more specifically we decided to exclude all women in whom infection with $N$ gonorrhoeae, yeasts, $T$ vaginalis, or herpes virus was found at the first visit, and all women from whom appreciable bacterial pathogens had been found in the urine or on high vaginal swabs on that oceasion.

The remaining 237 women (table IV) consisted of 188 without signs or symptoms indicating urethritis, 38 with symptoms but without signs, and only 11 with objective signs with or without symptoms. There was no significant difference in the overall rate of chlamydial infection, or in the proportion of

TABLE III Isolation of Chlamydia trachomatis from urethra and cervix in relation to presumptive urethritis* in 360 women

\begin{tabular}{|c|c|c|c|c|c|}
\hline \multirow[b]{2}{*}{ Condition } & \multicolumn{3}{|c|}{ No of women yielding chlamydiae from: } & \multirow{2}{*}{$\begin{array}{l}\text { Total (\%) } \\
\text { positive }\end{array}$} & \multirow{2}{*}{$\begin{array}{l}\text { No of urethral } \\
\text { isolates (\% of total } \\
\text { positive) }\end{array}$} \\
\hline & $\begin{array}{l}\text { Cervix } \\
\text { only }\end{array}$ & $\begin{array}{l}\text { Cervix }+ \\
\text { urethra }\end{array}$ & $\begin{array}{l}\text { Urethra } \\
\text { only }\end{array}$ & & \\
\hline $\begin{array}{l}\text { Urethritis* }(n=96) \\
\text { No urethritis }(n=264)\end{array}$ & $\begin{array}{r}4 \\
40\end{array}$ & $\begin{array}{l}29 \\
37\end{array}$ & $\begin{array}{l}4 \\
1\end{array}$ & $\begin{array}{l}37(39) \\
78(30)\end{array}$ & $\begin{array}{l}33(89) \\
38(49)\end{array}$ \\
\hline Total $(n=360)$ & 44 & 66 & 5 & $115(32)$ & $71(62)$ \\
\hline
\end{tabular}

*Presumptive urethritis = signs or symptoms, or both, suggesting urinary tract infection.

were from the group of 167 women with miscellaneous concurrent conditions, nine from 71 women with concurrent gonorrhoea, and 29 from the 122 contacts of men with NGU). Chlamydial infection was found in $37(39 \%)$ of the 96 women with urethritis, and 33 $(89 \%)$ of the 37 infected women had positive urethral swabs, but the urethra was the sole site of infection in only four $(11 \%)$ of them. Chlamydial infection was found in $78(30 \%)$ of the 264 women without signs or symptoms of urethritis, but only $38(49 \%)$ of these 78 infected patients had positive urethral swabs, and in only one case was the urethra the sole site of infection.

Thus the overall infection rate was slightly but not significantly greater in women with presumptive urethritis than in those without $\left(\chi^{2}=2 \cdot 2 ; \mathrm{p}>0 \cdot 1\right)$. The number of infected women who gave positive urethral swabs as well as or instead of positive cervical swabs, however, was significantly greater in the group with signs or symptoms of urethritis than in those without such evidence $\left(\chi^{2}=15 \cdot 7\right.$; $\mathrm{p}<0 \cdot 001)$. infected women who had urethral infection, between women with only symptoms and those with signs of urethritis. The overall rate of infection in women with signs or symptoms of urethritis, or both, was $39 \%$ (19/49 women), which was not significantly greater $\left(\chi^{2}=2 \cdot 7 ; p=0 \cdot 1\right)$ than in women with no such evidence $(48 / 188=26 \%)$. Urethral swabs were positive in $15 / 19(79 \%)$ chlamydia infected women with evidence of urethritis and in 21/48 (44\%) infected women with no such evidence $\left(\chi^{2}=5 \cdot 4\right.$; $\mathrm{p}=0 \cdot 02$ ).

\section{Discussion}

The high incidence of cervical infection with $C$ trachomatis found in contacts of men with NGU $(43 \%)$ and women with untreated gonorrhoea $(56 \%)$ in this study is not appreciably different from our earlier findings in unselected patients in the same STD clinic in Liverpool. ${ }^{2}$ The lower infection rate $(16 \%)$ in the group of women with miscellaneous conditions was to be expected, as it included women 
TABLE IV Incidence of infection with Chlamydia trachomatis in relation to presumptive urethritis in 237 women with no evidence of other genitourinary infections

\begin{tabular}{lrr}
\hline & No of women yielding chlamydiae: \\
\cline { 2 - 3 } Condition & Total (\%) positive & $\begin{array}{c}\text { From urethra }(\% \text { of } \\
\text { total positive) }\end{array}$ \\
\hline Presumptive urethritis: & $15(40)$ & $12(80)$ \\
Symptoms only $(\mathrm{n}=38)$ & $4(36)$ & $3(75)$ \\
Signs with or without symptoms $(\mathrm{n}=11)$ & $19(39)$ & $15(79)$ \\
Total $(\mathrm{n}=49)$ & $48(26)$ & $21(44)$ \\
No evidence of urethritis $(\mathrm{n}=188)$ & $67(28)$ & $36(54)$ \\
Total $(\mathrm{n}=237)$ & &
\end{tabular}

with a broad age range and a wide variety of reasons for visiting the clinic, including signs or symptoms of urethritis alone, but excluded those with gonorrhoea, or with sexual contacts with NGU.

Only 5/115 (4\%) infected women yielded positive results from the urethra alone, whereas $66 / 71(93 \%)$ of the women with positive urethral cultures also yielded positive results from cervical swabs, a situation very similar to that seen in gonorrhoea. ${ }^{45}$ Chlamydial infection could thus have been diagnosed from cervical swabs alone in $110 / 115(96 \%)$ women. Taking urethral in addition to cervical swabs would not appreciably improve the detection of chlamydial infection in STD clinics if introduced as a routine measure. Taking urethral swabs alone, instead of cervical swabs, would have grossly underestimated the true infection rate, as only $71 / 115(62 \%)$ of infected women would have been detected. These results are similar to those of Oriel et al, who did not find any case where $C$ trachomatis was isolated from the urethra but not from the cervix of contacts of men with NGU. ${ }^{6}$ Woolfitt and Watt found positive urethral swabs in only $21 / 53(40 \%)$ infected women, but the urethra was the sole positive site in five $(10 \%) .{ }^{7}$ In contrast, the urethra was the sole site of infection in 25/99 infected partners of men with NGU in Finland, whereas the cervix was the sole site in 28 and both sites were positive in $46 .^{8}$ As the urethra was positive in $72 \%$ and the cervix in $75 \%$ of patients in that series, the apparent advantage of urethral swabs seems to have been only relative, and was enhanced by a much lower rate of cervical isolation than has often been reported elsewhere.

Schachter considered that there was no definite evidence of $C$ trachomatis causing non-gonococcal urethritis of women, and that positive urethral cultures might represent merely anatomical contamination or sampling errors. ${ }^{9}$ Thus it is important to try to establish the validity of positive urethral swabs in women, who usually have concurrent infection of the cervix. In the study published here, clinical precautions were taken throughout to minimise cross contamination on examination and swabbing of the patient, but prior transfer of infected secretions from cervix to urethra obviously remained a possibility. However, a comparison of chlamydial inclusion counts from each type of swab in each positive woman strongly suggested, but obviously cannot prove, that the urethra and the cervix represented two independent sites of infection. In general, chlamydial inclusion counts from urethral cultures (range 2-3890, mean $172 \cdot 8$ ifu/coverslip) were much lower than from cervical cultures (range 1-35 250, mean 3972.4 ifu/coverslip). This difference in scale probably reflects the much smaller area of mucosa available for swabbing in the urethra. We regularly find similarly low counts in urethral swabs from men who have clinically overt urethritis. (In 107 untreated men with NGU who were found to be positive in the period of the study reported here, inclusion counts gave a range of $1-5170$, mean $617 \cdot 3$ ifu/coverslip.)

There has, however, been no unanimity of opinion on the relation of urethral infection to clinical urethritis in women. In 159 women attending an STD clinic in Atlanta, Georgia, USA, symptoms of urethritis were found in $32(20 \%)$; in 150 examined for $C$ trachomatis, $29(19 \%)$ gave positive cultures from urethra or cervix, six $(21 \%)$ of which were from the urethra only; but there was no significant difference in isolation rate from women with or without symptoms of urinary tract infection. ${ }^{10}$ In a gynaecological clinic in Finland, however, symptoms of urethritis were recorded in $38 / 71(54 \%)$ women with chlamydia positive urethral cultures but only in $6 / 28(21 \%)$ of those with positive cervical cultures only. ${ }^{8}$ In women attending a general medical practice in Ontario, C trachomatis was isolated from $30 / 100$ with urinary tract symptoms, but from only $2 / 30$ asymptomatic women. Isolations were from midstream specimens of urine alone in eight cases, from cervix and urine in two cases, and from cervix alone in $22 .{ }^{11}$ In the study reported here, 33/37 (89\%) chlamydial infections in women with signs or symptoms of urethritis, or both, affected the urethra in contrast with only $38 / 78(49 \%)$ infections in 
women without such evidence. These differences were significant $\left(\chi^{2}=15 \cdot 7 ; \mathrm{p}<0 \cdot 001\right)$. The mean urethral inclusion counts were no greater in women with evidence of urethritis than in those without.

A causal relationship between chlamydial infection of the urethra and urethritis cannot, however, be assumed without first excluding the possibility of other concurrent infective causes of this condition, and without differentiating between the many women with only symptoms (often vague) and those with objective signs of urethritis. Wallin et al found that urethral isolation rates of $C$ trachomatis in women with symptoms did not differ significantly from those without, but the isolation rate was $26 \%$ $(15 / 57)$ in women with 10 or more PMNL per microscopic field in urethral smears and only $5 \%(5 / 93)$ in those with fewer than 10 PMNL per field. ${ }^{10}$ Similarly, in women with acute urethral syndrome with no bacteruria, $C$ trachomatis was isolated from the cervix, the urethra, or both in $7 / 16(44 \%)$ women with pyuria, but from none of 16 women without pyuria. ${ }^{12}$

In the study reported here, the overall isolation rate of $C$ trachomatis in women with no evidence of bacteruria, gonorrhoea, or infection with trichomonas or yeasts was not appreciably greater in women with objective signs of urethritis than in those with only symptoms or with neither signs nor symptoms, and the proportion of infected women with positive urethral cultures was only 1.8 times greater in those with evidence of urethritis, than in those without. Furthermore, in 38/71 (54\%) women with positive urethral cultures, the infection was completely silent, as is often the case in urethral infection with $\mathrm{N}$ gonorrhoeae. Conversely, $C$ trachomatis was isolated from the urethra in only 3/11 $(27 \%)$ women with objective signs of urethritis who had no other demonstrable infective cause for their condition.

From these results it appears that chlamydial infection of the urethra is common, but is usually a concomitant of cervical infection. It seems unlikely that urethral swabs taken routinely in STD clinics would add to the overall detection of chlamydial infections or that they would sharply discriminate between women with urethritis and those without. Our findings, in common with those of other workers, suggest that a residual core of women with objective signs of urethritis but no other apparent pathogenic organism in the genitourinary tract do have $C$ trachomatis infection, which may explain their urinary tract signs. Very much wider clinical and pathological screening procedures and follow up of much larger populations than those used hitherto, however, will be essential to assess whether chlamydial urethral infection and urethritis are causally related.

\section{References}

1. Hobson D, Karayiannis P, Byng RE, Rees E, Tait IA, Davies JA. Quantitative aspects of chlamydial infections of the cervix. British Journal of Venereal Diseases 1980;56:156-62.

2. Tait IA, Rees E, Hobson D, Byng RE, Tweedie MCK. Chlamydial infections of the cervix in contacts of men with nongonococcal urethritis. British Journal of Venereal Diseases 1980;56:37-45.

3. Davies JA, Rees E, Hobson D, Karayiannis P. Isolation of Chlamydia trachomatis from Bartholin's ducts. British Journal of Venereal Diseases 1978;54:409-13.

4. Lucas JB, Price EV, Theyer JD, Schroeter A: Diagnosis and treatment of gonorrhoea in the female. $N$ Engl J Med 1967;276:1454-9.

5. Schmale JD, Martin JE Jr, Domescik G. Observations on the culture diagnosis of gonorrhoea in women. JAMA 1969; 210:312-4.

6. Oriel JD, Reeve $\mathbf{P}$, Powis $\mathbf{P}$, Miller A, Nicol CS. Chlamydial infection. Isolation of chlamydia from patients with nonspecific genital infection. British Journal of Venereal Diseases 1972; 48:429-36.

7. Woolfitt JMG, Watt L. Chlamydial infection of the urogenital tract in promiscuous and non-promiscuous women. British Journal of Venereal Diseases 1977;53:93-5.

8. Paavonen J. Chlamydia trachomatis-induced urethritis in female partners of men with nongonococcal urethritis. Sex Transm Dis 1979; 6:69-71.

9. Schachter J. Chlamydial infections. N Engl J Med 1978; 298:428-35.

10. Wallin JE, Thompson SE, Zaidi A, Wong K-H. Urethritis in women attending an STD clinic. British Journal of Venereal Diseases 1981;57:50-4.

11. Sorbie J, O'Shaughnessy MV. Chlamydia trachomatis infections in women with urogenital symptoms. Can Med Assoc J 1982; 127:974-6.

12. Stamm WE, Wagner KF, Amsel R, et al. Causes of the acute urethral syndrome in women. N Engl J Med 1980;303:409-15. 